\title{
Fate and transport of radiocesium in urban building materials
}

\author{
A. Gusarov¹, N. Il'icheva ${ }^{1}$, A. Konoplev¹, S.D. Lee ${ }^{2}$, K. Maslova1 ${ }^{1}$, V. Popov ${ }^{1}$ \\ and I. Stepina ${ }^{1}$ \\ ${ }^{1}$ RPA "Typhoon", Obninsk, Kaluga region 249038, Russia \\ ${ }^{2}$ National Homeland Security Research Center, U.S. Environmental Protection Agency, \\ Research Triangle Park, NC 27711, USA
}

\begin{abstract}
Fine radioactive particulate dispersal in outdoor areas presents significant economic, social, environmental and public health concerns. The interactions of these radioactive particles with urban surfaces need to be well understood to develop optimized decontamination strategies. The major environmental factors influencing these interactions are relative air humidity, temperature and rain. The objective of this work is to investigate the fate and transport of water soluble cesium deposited on conventional urban building materials, especially concrete, brick, asphalt, limestone, and granite, under various environmental conditions (relative humidity (RH), and atmospheric precipitation). The data on the kinetics of ${ }^{137} \mathrm{Cs}$ desorption from building materials by the solution containing $100 \mathrm{MM}$ of $\mathrm{Ca}^{2+}$ and $0.5 \mathrm{MM}$ of $\mathrm{K}^{+}$have shown that the shape of the ${ }^{137} \mathrm{Cs}$ desorption curves is similar for all building materials. There is a rapid initial decrease in the activity of the sorbed ${ }^{137} \mathrm{Cs}$. The desorption rate first decreases quickly during $7-10$ days and practically does not change later. The remaining ${ }^{137} \mathrm{Cs}$ in building materials that is not desorbed by the solution is $30-40 \%$ of the initially sorbed amount. For the building materials of interest, radiocaesium interception potentials (RIP). The RIP(K) value has been shown to range from 20 to $300 \mathrm{mM} / \mathrm{kg}$ and increase in the order: limestone $>$ brick $>$ concrete $>$ granite $>$ asphalt. The fine fraction of building materials $(<0.125 \mathrm{~mm})$ sorbs ${ }^{137} \mathrm{Cs}$ better than the coarse fraction $(0.0125-0.25 \mathrm{~mm})$. Based on RIP(K) value and measured concentration of cations the distribution coefficients $\mathrm{K}_{\mathrm{d}}\left({ }^{137} \mathrm{Cs}\right)$ were determined. The study of the mechanisms of radiocesium binding by different components of building materials, based on sequential extraction technique, shows that the highest ability to bind ${ }^{137} \mathrm{Cs}$ is characteristic of asphalt which retains $40.9 \pm 1.0 \%$ of ${ }^{137} \mathrm{Cs}$ after all extractions. By the ability to bind ${ }^{137} \mathrm{Cs}$ with the residual fraction, the studied materials form the following sequence: concrete $>$ limestone $>$ granite $>$ brick. Method to study radionuclides distribution in depth of building materials using layer-by-layer grinding has been developed.
\end{abstract}

\section{INTRODUCTION}

It is important to develop decontamination and clean-up technologies after incidents that involve radioactive particulates dispersed in an urban area. Fine radioactive particulate dispersal in outdoor areas presents significant economic, social, environmental and public health concerns. The interactions of these radioactive particles with urban surfaces need to be well understood to develop optimized decontamination strategies. An expanded understanding of these interactions under varied atmospheric conditions will aid in the development of more effective decontamination techniques and strategies $[1,2]$. The objective of this work is to investigate fate and transport of water soluble cesium deposited on common urban building materials, especially concrete, brick, asphalt, limestone, and granite, under various environmental conditions (relative humidity $(\mathrm{RH})$, and atmospheric precipitation).

\section{MATERIALS AND METHODS}

Building materials of asphalt, brick, granite, concrete and limestone have been studied. Material coupons have been powdered and three granulometric fractions have been obtained: $<0.125 ; 0.125-$ $0.25 ;>0.25 \mathrm{~mm}$ (Table 1). Principal physical properties of building materials under study are presented 
Table 1. Distribution of building material powders by granulometric fractions.

\begin{tabular}{|l|c|c|c|c|c|}
\hline \multirow{2}{*}{ Fraction, mm } & \multicolumn{5}{|c|}{ Proportion \% } \\
\cline { 2 - 6 } & Asphalt & Brick & Granite & Concrete & Limestone \\
\hline$<0.125$ & 42.8 & 36.8 & 53.3 & 53.3 & 100 \\
\hline $0.125-0.25$ & 38.7 & 23.5 & 46.7 & 45.5 & 0 \\
\hline$>0.25$ & 18.5 & 39.7 & 0 & 1.2 & 0 \\
\hline
\end{tabular}

Table 2. Selected physical properties of building materials.

\begin{tabular}{|l|c|c|c|}
\hline & $\begin{array}{c}\text { Porosity, } \\
\mathrm{cm}^{3} / \mathrm{cm}^{3}\end{array}$ & $\begin{array}{c}\text { Specific weight, } \\
\mathrm{g} / \mathrm{cm}^{3}\end{array}$ & Hygroscopic moisture, \% \\
\hline Concrete & 0.32 & 2.73 & 0.4 \\
\hline Granite & 0.053 & 2.77 & 0.02 \\
\hline Limestone & 0.174 & 2.72 & 0.03 \\
\hline Asphalt & 0.194 & 2.71 & 0.095 \\
\hline Brick & 0.311 & 2.77 & 0.07 \\
\hline
\end{tabular}

Table 3. Elemental composition of Total content of building materials.

\begin{tabular}{|l|c|c|c|c|c|}
\hline & Asphalt & Limestone & Brick & Granite & Concrete \\
\hline & \multicolumn{5}{|c|}{ Macroelements, g/kg } \\
\hline $\mathrm{K}$ & 5.87 & 0.223 & 15.9 & 26.6 & 7.61 \\
\hline $\mathrm{Na}$ & 23.2 & 0.543 & 20.9 & 40.9 & 4.55 \\
\hline $\mathrm{Ca}$ & 26.3 & 530 & 10.7 & 124 & 29.4 \\
\hline $\mathrm{Mg}$ & 21.8 & 8.56 & 30.6 & 3.27 & 11.5 \\
\hline $\mathrm{Fe}$ & 43.0 & 0.655 & 37.5 & 9.03 & 27.6 \\
\hline $\mathrm{Al}$ & 66.6 & 0.461 & 84.2 & 84.9 & 40.8 \\
\hline
\end{tabular}

in Table 2. The ability of radionuclides to be sorbed largely depends on the chemical composition of building materials. Data on elemental composition of the building materials are shown in Table 3. Note the significant amount of calcium in limestone.

\section{RESULTS AND DISCUSSION}

The kinetics of ${ }^{137} \mathrm{Cs}$ sorption by the powdered building materials was studied in aqueous suspension at $20^{\circ} \mathrm{C}$ for the interaction time $1,7,14$ and 28 days. For concrete, limestone and brick the maximum degree of adsorption was seen after 24 hours of interaction, while for asphalt and granite it occurred after 6 days (Figure 1). In addition the ${ }^{137} \mathrm{Cs}$ sorption kinetics by building materials was determined using the dynamic method of investigating the ${ }^{137} \mathrm{Cs}$ sorption from the solution containing $100 \mathrm{MM}$ of $\mathrm{Ca}^{2+}$ and $0.5 \mathrm{MM}$ of $\mathrm{K}^{+}$. Like in suspensions, sorption of ${ }^{137} \mathrm{Cs}$ by concrete and limestone from this solution becomes maximum in 24 hours of interaction. For asphalt and concrete the sorption equilibrium is established during about 3 days at $35^{\circ} \mathrm{C}$. Unlike the experiments with suspensions, the ${ }^{137} \mathrm{Cs}$ sorption equilibrium for brick sets in slower (15-20 days). The differences in the kinetics of ${ }^{137} \mathrm{Cs}$ sorption for the two methods can be explained by the fact that the studies were conducted at different temperature and under different conditions (no kinetic resistance in the film surrounding the sorbent particles in case of the limited volume method).

The data on the kinetics of ${ }^{137} \mathrm{Cs}$ desorption from building materials by the solution containing $100 \mathrm{MM}$ of $\mathrm{Ca}^{2+}$ and $0.5 \mathrm{MM}$ of $\mathrm{K}^{+}$have shown that the shape of the ${ }^{137} \mathrm{Cs}$ desorption curves is similar for all building materials. There is a rapid initial decrease in the activity of the sorbed ${ }^{137} \mathrm{Cs}$. The desorption rate first decreases quickly during 7-10 days and practically does not change later. The remaining ${ }^{137} \mathrm{Cs}$ in building materials that is not desorbed by the solution is $30-40 \%$ of the initially sorbed amount. 


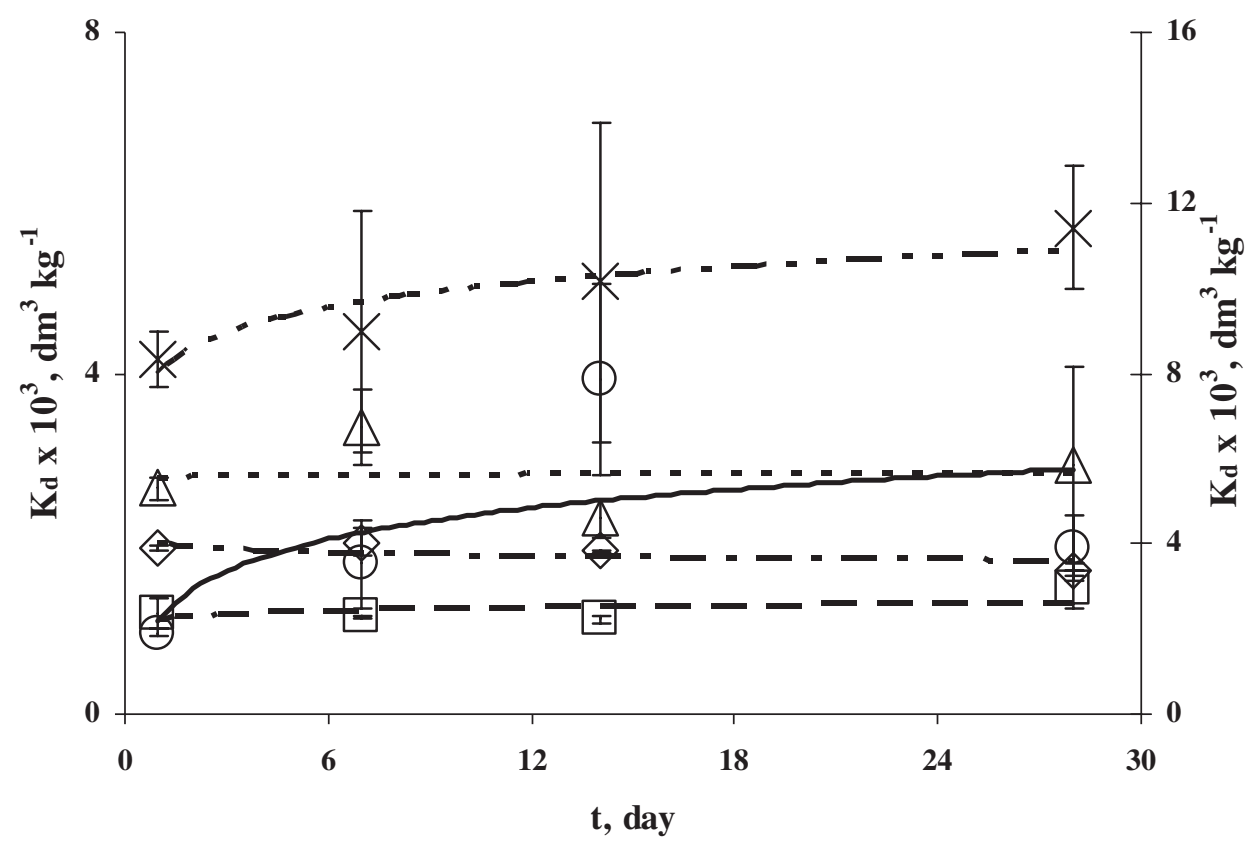

Figure 1. Kinetics of the distribution coefficients $\mathrm{K}_{\mathrm{d}}\left({ }^{137} \mathrm{Cs}\right)$ in building materials at $20^{\circ} \mathrm{C}: \times$-asphalt; $\triangle$-granite; $\diamond$-concrete; o-limestone; $\square$-brick.

Table 4. Radiocesium interception potentials $\mathrm{RIP}(\mathrm{K})$ and $\mathrm{RIP}(\mathrm{N})$ in the building materials per absolutely dried weight.

\begin{tabular}{|l|c|c|c|c|}
\hline \multirow{2}{*}{} & \multicolumn{2}{|c|}{$\mathrm{RIP}(\mathrm{K}), \mathrm{mmol} / \mathrm{kg}$} & \multicolumn{2}{c|}{$\mathrm{RIP}(\mathrm{N}), \mathrm{mmol} / \mathrm{kg}$} \\
\cline { 2 - 5 } & $<0.125$ & $0.125-0.25$ & $<0.125$ & $0.125-0.25$ \\
\hline Asphalt & $280.44 \pm 16.3$ & $135.80 \pm 10.7$ & $29.45 \pm 0.58$ & $20.77 \pm 0.078$ \\
\hline Limestone & $12.45 \pm 0.43$ & - & $1.90 \pm 0.24$ & - \\
\hline Granite & $204.38 \pm 21.5$ & $36.57 \pm 2.58$ & $11.44 \pm 0.87$ & $3.21 \pm 0.062$ \\
\hline Concrete & $185.35 \pm 5.10$ & $68.57 \pm 1.83$ & $195.43 \pm 1.51$ & $44.56 \pm 0.054$ \\
\hline Brick & $14.93 \pm 3.03$ & $9.62 \pm 1.25$ & $5.35 \pm 0.57$ & $2.36 \pm 0.22$ \\
\hline
\end{tabular}

For the building materials of interest, radiocesium interception potentials (RIP) were determined with respect to potassium ions $\mathrm{RIP}(\mathrm{K})$ and ammonium according to the methodology [3], as well as the selectivity coefficients values for exchange of potassium and ammonium ions $K_{c}(K / N)$ on the selective sorption sites (Table 4). The RIP(K) value has been shown to range from 20 to $300 \mathrm{mM} / \mathrm{kg}$ and increase in the order: limestone $>$ brick $>$ concrete $>$ granite $>$ asphalt. The fine fraction of building materials $(<0.125 \mathrm{~mm})$ sorbs ${ }^{137} \mathrm{Cs}$ better than the coarse fraction $(0.0125-0.25 \mathrm{~mm})$. The extent to which sorption varies for different materials, however, is different: from 1.5 for granite to 15 for asphalt. The value of $\mathrm{K}_{\mathrm{c}}(\mathrm{K} / \mathrm{N})$ varies from 1.5-2.8 for concrete and brick to 7-18 for asphalt, limestone and granite, which suggests a possible impact of clay particles, such as illite, on the ${ }^{137}$ Cs sorption. Based on RIP(K) value and measured concentration of cations the distribution coefficients $\mathrm{Kd}\left({ }^{137} \mathrm{Cs}\right)$ were determined.

Based on the desorption kinetics curves the mechanisms of the ${ }^{137} \mathrm{Cs}$ sorption by building materials

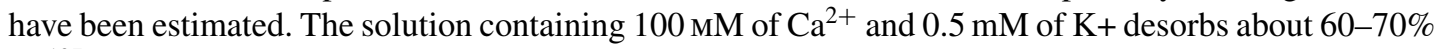
of ${ }^{137} \mathrm{Cs}$ in 10-30 days. The study of the mechanisms of radiocesium binding by different components of building materials, based on sequential extraction technique, shows that the highest ability to bind ${ }^{137} \mathrm{Cs}$ is characteristic of asphalt which retains $40.9 \pm 1.0 \%$ of ${ }^{137} \mathrm{Cs}$ after all extractions. By the ability 


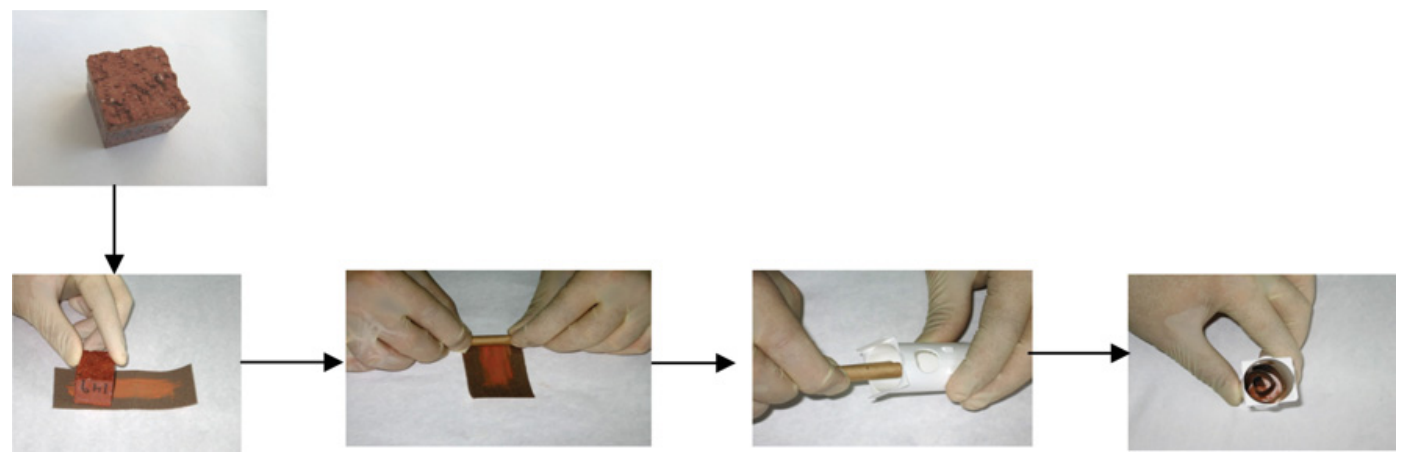

Figure 2. Sequence of steps for building material grinding.
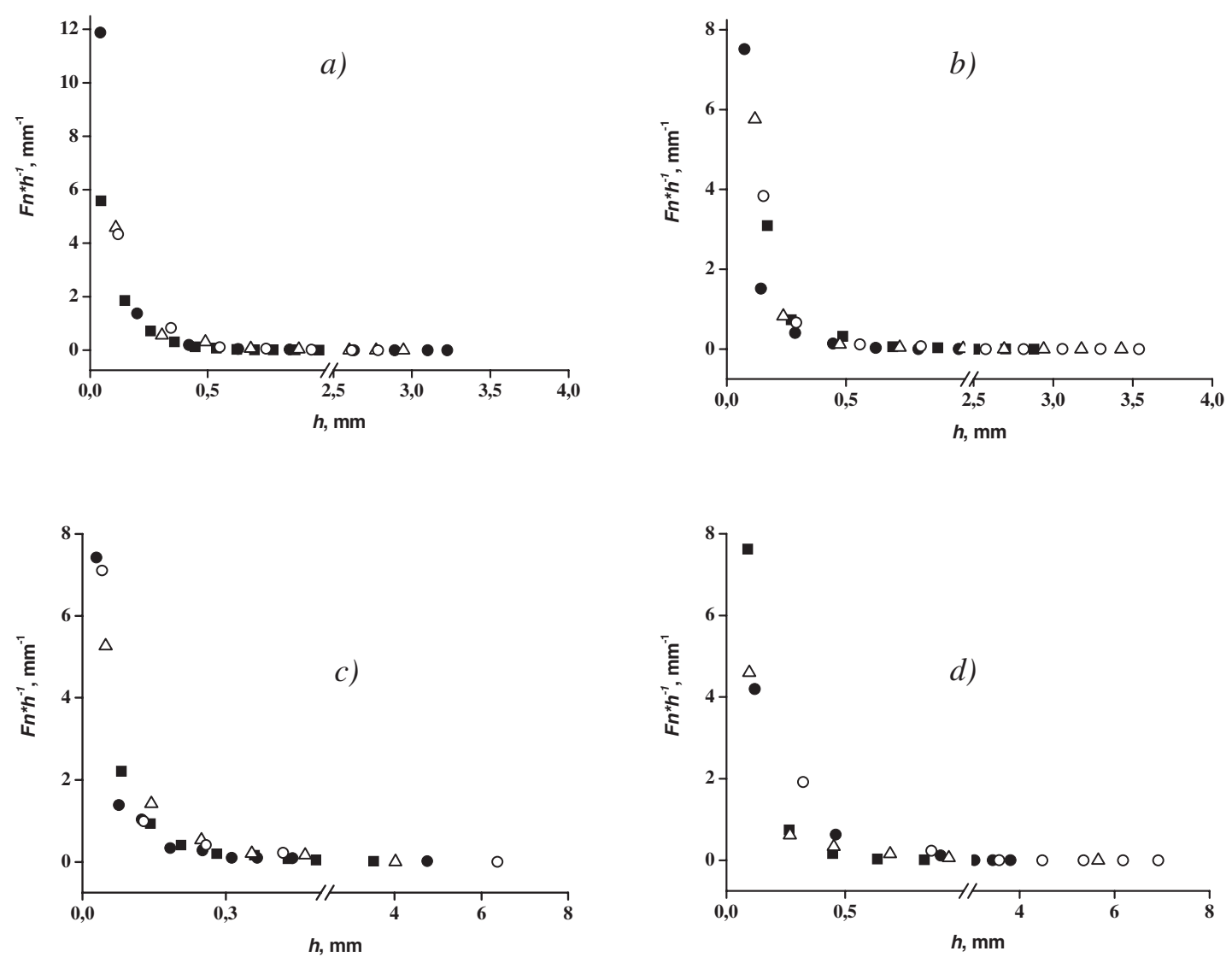

Figure 3. Depth distribution of ${ }^{137} \mathrm{Cs}$ in building materials as a function of interaction time $(\mathbf{\square}-1$ day, $\diamond-$ 7 days, $\triangle-14$ days, $\circ-28$ days) a) brick, humidity $30 \%$; b) brick, humidity $85 \%$; c) limestone, humidity $30 \%$, d) limestone, humidity $85 \%$.

to bind ${ }^{137} \mathrm{Cs}$ with the residual fraction, the studied materials form the following sequence: concrete $>$ limestone $>$ granite $>$ brick.

The fractions of the exchangeable ${ }^{137} \mathrm{Cs}$ in the powdered building material samples after sorption during 24 hours from the solution with the potassium adsorption ratio 0.05 are as follows: $24.2 \pm 1,0 \%$ for limestone, $8.9 \pm 1,3 \%$ for granite, $38.4 \pm 1,5 \%$ for concrete, $8.5 \pm 0,3 \%$ for asphalt. 
Effective method to study radionuclides distribution in depth of building materials using layer-bylayer grinding has been developed (Figure 2). Using the developed method, the ${ }^{137} \mathrm{Cs}$ distribution in depth of selected building materials at different air humidity and time at $20^{\circ} \mathrm{C}$ was studied (Figure 3). More than $90 \%$ of applied activity in limestone is distributed in the surface layer to the depth of $1.5 \mathrm{~mm}$. There have not been detected any obvious dependence on relative air humidity and incubation time. On the other hand, for ${ }^{137} \mathrm{Cs}$ distribution in the layer more than $0.2 \mathrm{~mm}$ a weak dependence of the profile on interaction time and relative air humidity can be seen. With respect to ${ }^{137} \mathrm{Cs}$ distribution in depth of brick and concrete, that there is no clear impact of incubation and relative air humidity on the shape of ${ }^{137} \mathrm{Cs}$ depth distribution curves. Nevertheless it needs to be emphasized that $95 \%$ of applied ${ }^{137} \mathrm{Cs}$ occurs in the layer $0-1.0 \mathrm{~mm}$ for brick and $0-0.5 \mathrm{~mm}$ for concrete.

\section{Acknowledgment}

The work was funded by US Environmental Protection Agency through Partner Project with International Science and Technology Center (ISTC Project \#4007)

\section{References}

[1] Lee, C. P., Kuo, Y. M., Tsai, S. C., Wei, Y. Y., Teng, S. P., and Hsu, C. N. Journal of Radioanalytical and Nuclear Chemistry, Volume 275 (2008) 343-349.

[2] Real, J., Persinb, F., and Camarasa-Claret, C. Journal of Environmental Radioactivity, Volume 62 (2002) 1-15.

[3] Wauters J., Elsen A., Cremers A., Konoplev A.V., Bulgakov A.A. and Comans R.N.J. Applied Geochemistry Volume 11 (1996) 589-594. 